\title{
Evaluation of the Integrated Primary Care Clinic Into Behavioral Care Setting
}

\author{
Jarman Alqahtani ${ }^{1} \&$ Daniel West ${ }^{2,3}$ \\ ${ }^{1}$ Ministry of Health, Saudi Arabia \\ ${ }^{2}$ FACHE, FACMPE, University of Scranton, Scranton, PA, USA \\ ${ }^{3}$ Teresa Lacey, RN, Wright Center for Graduates Medical Education, Scranton, PA, USA \\ Correspondence: Jarman Alqahtani, Ministry of Health, Saudi Arabia.
}

Received: August 29, 2018 Accepted: October 6, 2018 Online Published: October 24, 2018

doi:10.5539/gjhs.v10n11p169 URL: https://doi.org/10.5539/gjhs.v10n11p169

\begin{abstract}
Objective: The study has aimed to explore the process, outcomes of primary care, and barriers that make the primary care access difficult for the patients.

Design and Setting: The study has utilized quantitative and qualitative approach and collected data from the clinic and patients. Patient survey was conducted to ask the patients about the possible reasons, which prevent them from accessing primary care services in the past.

Results: The mean age of patients was 46 years, among which majority (65\%) were males. The results showed that education was the significant factor in determining the health status of a specific population. The clinic was successfully integrated into the behavioral health care setting. Many patients had been enrolled in the clinic for the first time with the help of a care manager that facilitated the identification of those patients. Most commonly, transportation was the main barrier for those populations for not seeking the primary care services. Emergency department use significantly declined after the implementation of the new model that reduced the cost of health services dramatically in a short period of time i.e. 6 months.
\end{abstract}

Conclusion: There are susceptical gaps within the fragmented care due to high rates of physical health conditions. Majority of the patients in the study sample were satisfied with the new model; therefore, the new model was termed as effective and efficient.

Keywords: primary care, clinic, behavioral care, healthcare

\section{Introduction}

Traditional healthcare models are likely to ignore the connection between mental and physical health and approach towards the mental and physical health separately (Varcarolis, 2016). However, in the recent times, healthcare services have evolved for the development of a progressive model of integrated care (Corrigan et al., 2014). A primary care clinic was established in September 2015 inside the Scranton Counseling center by Wright Center for the integration of mental health services within the primary care clinics. The counseling center provides mental health care to the people living in Lackawanna county of Pennsylvania. Moreover, primary care services were provided on-site and collaboration with mental health services associated with integrated healthcare model, which was proposed by the Wright Center.

A study has shown that the healthcare costs of treating patients with depression and anxiety is around $50-75 \%$ greater as compared to the patients without mental disorders (Simon \& VonKorff, 1997). The treatment cost is higher among the patients with mental problems as it degrades their physical health also. In 1960, the programs integrated with behavioral health were originated within the primary care (Cummings \& Cummings, 1977). A great number of programs have been implemented and evaluated rigorously after the enthusiasm for the integrated models was revived in 1990; for instance, the case of Hawaii Medicaid study (Van Mierlo et al., 2014). Behavioral health care setting is carried out by behavioral and primary care providers to overcome the behavioral complications of the patient (Ward et al., 2016). The entire population residing in Oahu (Honolulu) comprising of 36,000 people was assigned to usual care or integrated model, randomly. The patients visit a psychotherapist, as they provided with integrated care (Stuart, 2014). Hence, behavioral health care setting is aimed to correct the 
behavioral consequences of a patient diagnosed with mental illness, the treatment is not limited to hospitals and behavioral healthcare providers can utilize the telephone services or meet patients to improve their behavior (Ward et al., 2016). The experimental results revealed that the cost of integrated care is likely to be recovered by the medical-surgical cost savings within 18 months. However, there was continuous and significant reduction in medical utilization (Pallak, 1993). The establishment of primary care within mental health clinics is not the typical way to integrate the behavioral health in primary care setting; however, the outcome is supposed to be the same. The mental health center is likely to provide following primary care services;

- Meet the physical health needs of patients effectively.

- Improve physical functioning and health of the patients.

- Improve the quality and the efficiency of the health care delivery.

An integrated program named IMPACT, designed for the elderly people was implemented and evaluated around 18 clinics in five different states. These patients needed to visit nurse to cope up with their mental health issues. The effectiveness of integrated healthcare was demonstrated on the basis of a true experimental design. However, it has been shown that there is a significant improvement in depression and physical functioning of the patients in the integrated model as compared to the patients suffering depression in usual care (Bakitas et al., 2015). The costs were slightly lesser than the traditional medical model after one year of operation (Callahan et al., 2005; Katon et al., 1995). Similarly, a statistically significant benefit of integrated care was revealed through the cumulative meta-analysis of 37 studies (Gilbody et al., 2006). The study observed significant improvement in the depression outcomes after 6 hours that had long-lasting benefit of up to five years. Cost advantage of integrated care and costs approximate of primary care have been suggested by some studies (Callahan et al., 2005; Katon et al., 1995).

This study has been designed to explore the process and the outcome of the primary care and determine what possible barriers make the primary care access difficult for those patients. As a process evaluation, the study has explored the integration and implementation of the primary care to mental care. Moreover, the study has evaluated the effectiveness of primary care clinic and its efforts applied for health and well-being of patients as an outcome evaluation.

\section{Methodology}

The study has utilized quantitative and qualitative data to accomplish the evaluation goals. The existing data from clinic and data collected from patients were the main data sources. Patient survey instrument was developed for the purpose of this project. The questionnaire was used as a tool for data collection. The study was conducted for the period from September 1, 2015 to February 29, 2016. Table 1 has summarized the evaluation of the data sources and measures used in conducting this study.

Table 1. Evaluating goals/objectives, data sources, and measures

\begin{tabular}{|c|c|c|c|}
\hline Evaluation Goal & Evaluation Objective & Data Source & Measures \\
\hline \multirow{4}{*}{ Evaluation process } & $\begin{array}{l}\text { Primary care physicians } \\
\text { in-house, integrated, and } \\
\text { collaborative }\end{array}$ & $\begin{array}{l}\text { Interviews with } \\
\text { administrative staff and } \\
\text { site visits }\end{array}$ & $\begin{array}{l}\text { Process interviews and observation } \\
\text { during site visits }\end{array}$ \\
\hline & Describe patients served & Patient Survey & $\begin{array}{l}\text { Total number of clients seen by the } \\
\text { physical health specialist and the total } \\
\text { number of visits. }\end{array}$ \\
\hline & Describe patient profile & Patient survey & $\begin{array}{l}\text { Descriptive profile (age, sex, } \\
\text { race/ethnicity, and education) }\end{array}$ \\
\hline & $\begin{array}{l}\text { Patient's barriers to access } \\
\text { primary care in the past }\end{array}$ & Patient survey & Descriptive barriers \\
\hline \multirow{2}{*}{$\begin{array}{l}\text { Evaluate } \\
\text { Efficiency }\end{array}$} & $\begin{array}{l}\text { Reduce utilization of } \\
\text { emergency department } \\
\text { (ED) }\end{array}$ & Patient survey & $\begin{array}{l}\text { Number of visits to ED before and after } \\
\text { enrollment in the primary care clinic. }\end{array}$ \\
\hline & Improve access & Clinic data & $\begin{array}{l}\text { Percentage of patients receiving physical } \\
\text { health services who have not received } \\
\text { such services before }\end{array}$ \\
\hline
\end{tabular}




\begin{tabular}{|c|c|c|c|}
\hline $\begin{array}{l}\text { Evaluate Outcomes- } \\
\text { Physical Health and } \\
\text { Functioning }\end{array}$ & $\begin{array}{l}\text { Improve objective } \\
\text { indicators of physical } \\
\text { health and functioning }\end{array}$ & Clinic data & $\begin{array}{l}\text { Diabetes outcome-baseline } \mathrm{HbA1c} \text { to } \\
\text { assess control and when feasible, follow } \\
\text { up HbA1c to assess efficacy }\end{array}$ \\
\hline $\begin{array}{l}\text { Evaluate Outcomes- } \\
\text { Experience }\end{array}$ & Improve experience & Patient survey & Qualitative patients' comparisons \\
\hline
\end{tabular}

Patient survey was distributed to 49 patients and they were asked about the possible reasons, which prevent them from accessing primary care services in the past.

\section{Results}

The clinic had enrolled 362 patients in its first six months of operation. Of those 362,145 were new patients and 217 were follow-up patients. There were 1,304 clinic encounters, with an average of 60 visits per month. The demographic profile of 49 patients in the primary care clinic has been presented in table 2. Majority of the patients who attended the clinic were older than 46 years and younger than 55 years old. The average age of the patient was 46 years. Majority of patients were male (56\%). The majority of the patient population race tends to be white (77\%) followed by unidentified race (15.3\%). Majority of the population (87.20) was not Hispanic or Latino. Approximately $43.5 \%$ of patients did not complete the high school and $38.5 \%$ were having some college. It seems that education is a significant factor in determining the health of a specific population. A significant number of patients suffer hypertension (28\%) and diabetes mellitus (20\%). Figure 1 has provided 6 top most diagnosed physical health among those patients.

Table 2. Demographic details

\begin{tabular}{ll}
\hline Demographic Characteristic & Percent \\
\hline Age: & $23 \%$ \\
$\mathbf{1 8}-\mathbf{3 5}$ & $20.5 \%$ \\
$\mathbf{3 6}-\mathbf{4 5}$ & $36 \%$ \\
$\mathbf{4 6}-\mathbf{5 5}$ & $13 \%$ \\
$\mathbf{5 6}-\mathbf{6 5}$ & $7.5 \%$ \\
$\mathbf{\mathbf { 6 5 }}$ & \\
\hline Sex: & $56 \%$ \\
Male & $44 \%$ \\
Female & \\
\hline Race: & $0 \%$ \\
American Indian or Alaska Native & $0 \%$ \\
Asian & $7.7 \%$ \\
Black or African American & $0 \%$ \\
Native Hawaiian or Another Pacific Islander & $77 \%$ \\
White & $15.3 \%$ \\
Other & \\
\hline Ethnicity: & $12.8 \%$ \\
Hispanic or Latino & $87.2 \%$ \\
\hline Not Hispanic or Latino & \\
\hline Education: & $43.5 \%$ \\
Did not complete high school & $38.5 \%$ \\
High school/GED & $10.5 \%$ \\
\hline Some college &
\end{tabular}




\begin{tabular}{ll}
\hline Bachelor's degree & $2.5 \%$ \\
Master's degree & $0 \%$ \\
Advanced graduate work & $0 \%$ \\
Not sure & $5 \%$ \\
\hline
\end{tabular}

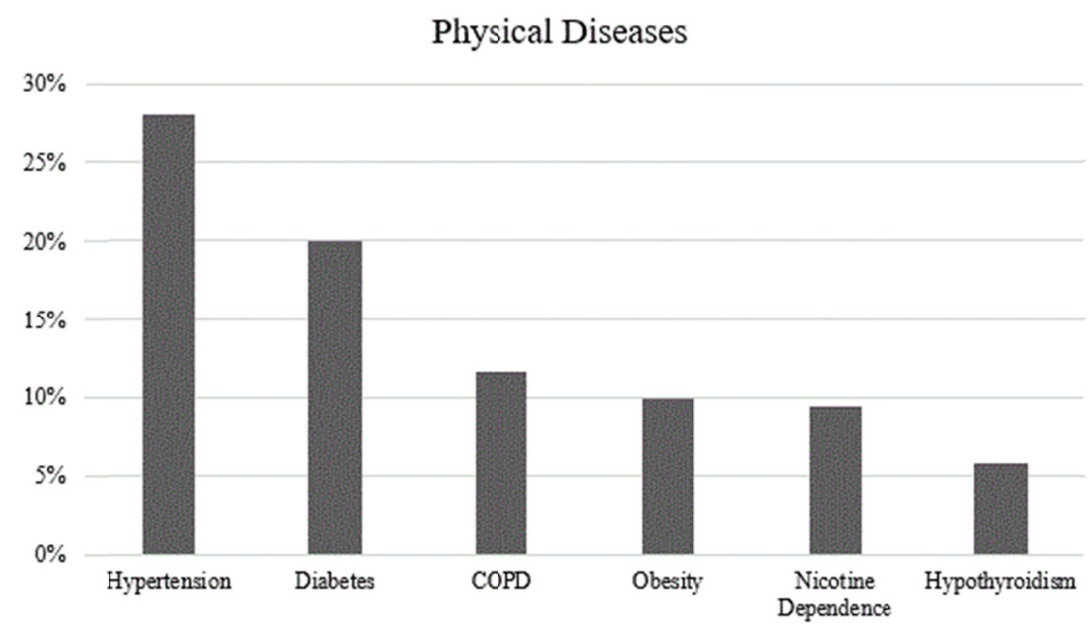

Figure 1. Top physical diseases

\subsection{Patient's Barriers to Access the Primary Care}

The results revealed that the most common barrier to access primary care was the transportation barrier (48\%), followed by their realization that the visit to the primary care physician was not important (27\%) (Figure 2). This result indicated that the social determinants of health are an important predictor of the health outcome. Policy makers and community leaders should advocate to promote the social well-being of the community. Health education is an important strategy to promote the physical well-being of the individuals. The patients need to be provided with pertinent information to address the need of having a primary care physician to prevent and monitor some of the risk factors. These risk factors are capable to exacerbate the mental illness or make the patient vulnerable to develop physical illnesses.

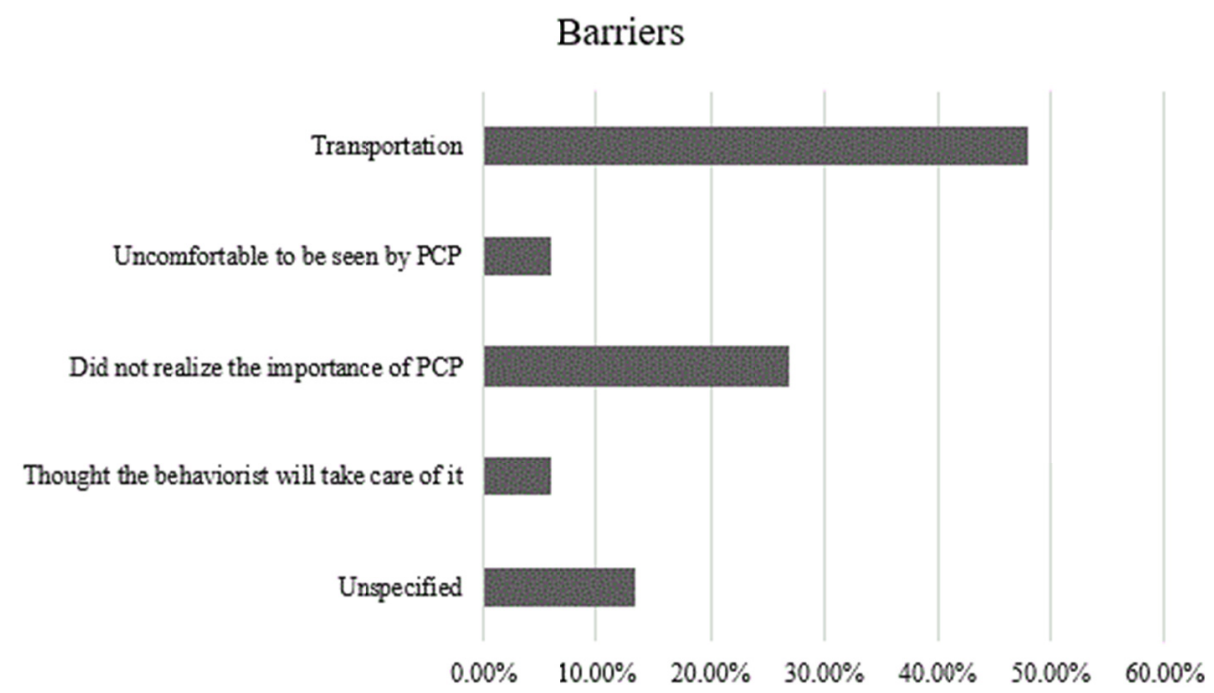

Figure 2. Barriers in accessing primary health care services 


\subsection{Outcome Evaluation}

Primary care is used by the patients appropriately; for instance, these patients reduce their visits to ER, when those services are unable to address their physical mental health issues. For this purpose, the visits of ER have been measured for six months before integration and six months after utilization of ED. There were 143 visits to the ER six months prior to the integration (Figure 3).

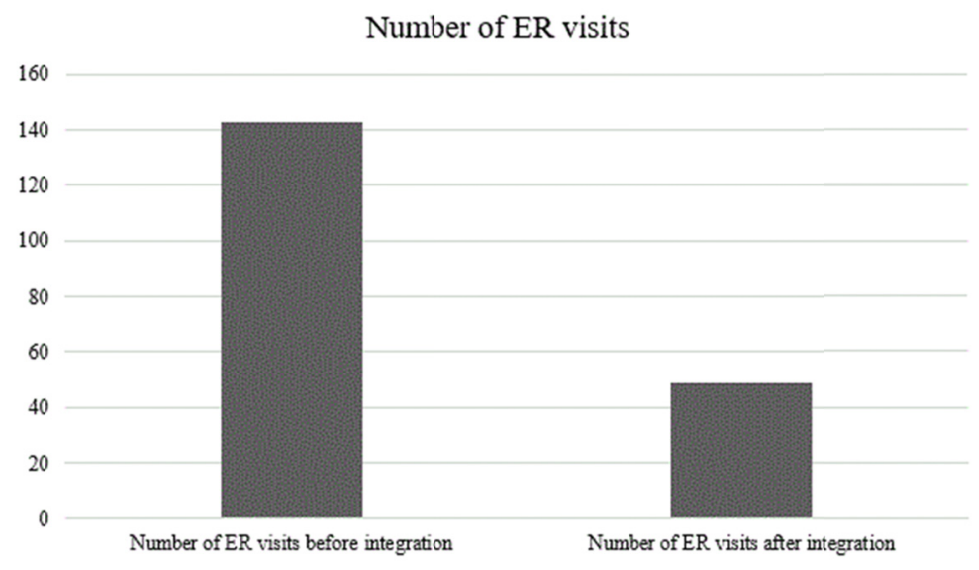

Figure 3. Number of ER visits

The results showed that the mean of the ED visits before and after the enrollment in the primary care was 2.86 and 0.98 , respectively. The $P$ value of t-test (1.51E-05) is smaller than $5 \%$ (assumed alpha). There is significant difference in the mean ED visits of the patients before and after attending the primary care clinic. Statistically significant difference in the utilization of $\operatorname{ED}(P$ value $<0.05)$ was found. The results signified the clinic to be an effective approach for reducing the healthcare costs incurred by visiting ED units and also improve the access to these clinics.

\subsection{Improving Physical Health of Patients}

Determining the effect of the integration on physical health is an important factor to assess the effectiveness and the outcome of such integration. Majority of patients have hypertension and diabetes mellitus. The outcome and control of diabetes has been evaluated by assessing the baseline and follow up HbAlc. The average plasma glucose concentration is calculated through $\mathrm{HbAlc}$, which is referred to as glycated hemoglobin (A1c). HbAlc for people with diabetes is below $7 \%(<154 \mathrm{mg} / \mathrm{dl})$ (Diabetes care, 2014) (Table 3 and Figure 4).

Table 3. HbA1c level and the corresponding blood glucose sugar level

\begin{tabular}{lll}
\hline & Mean Plasma Glucose & \\
\hline HbA1c (\%) & $\mathbf{m g} / \mathbf{d l}$ & $\mathbf{m m o l} / \mathbf{l}$ \\
$\mathbf{6}$ & 126 & 7.0 \\
$\mathbf{7}$ & 154 & 8.6 \\
$\mathbf{8}$ & 183 & 10.2 \\
$\mathbf{9}$ & 212 & 11.8 \\
$\mathbf{1 0}$ & 240 & 13.4 \\
$\mathbf{1 1}$ & 269 & 14.9 \\
$\mathbf{1 2}$ & 298 & 16.5 \\
\hline
\end{tabular}




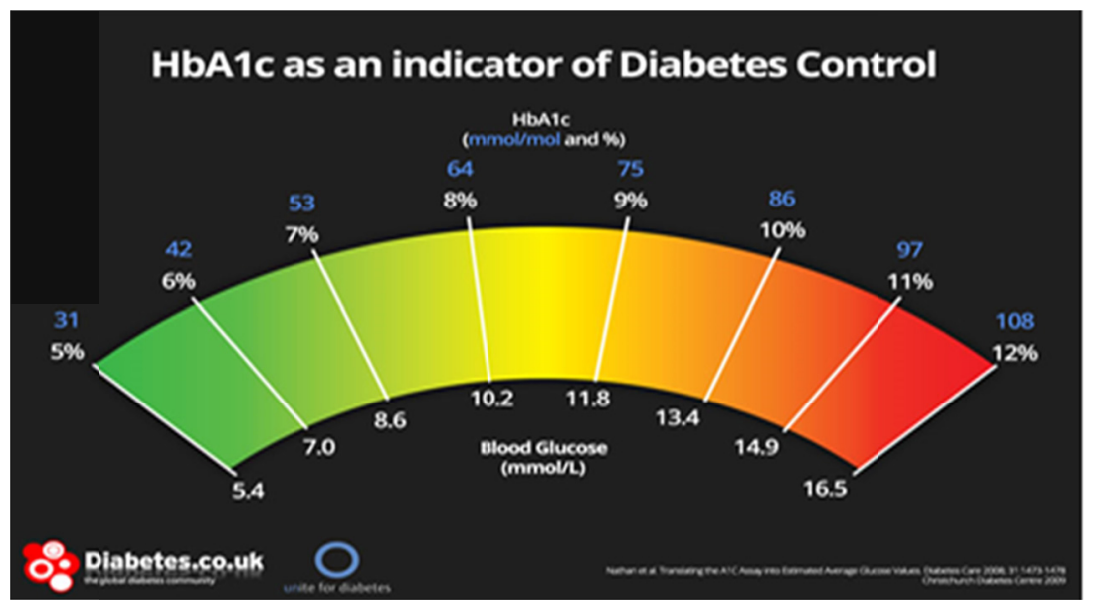

Figure 4. HbA1c as an indicator of diabetes control

There were about 72 patients (20\%) diagnosed with diabetes for the first time upon enrolling in the new clinic. Baseline HbAlc were identified for only 9 patients. Out of 72 diabetic patients, only 9 patients had baseline $\mathrm{HbAlc}$ in their records. The average HbAlc for those 9 patients was $7.52 \mathrm{mmol} / \mathrm{L}$, which indicated that their diabetes is not well controlled (the target HbA1c should be below $7 \mathrm{mmol} / \mathrm{L}$ ).

\subsection{Patient Satisfaction}

Patients in the study sample (49 patients) were asked about their experience and satisfaction of the care provided by the primary care clinic. The results showed that majority of patients were extremely and very satisfied about the care ( $49 \%$ and $38.2 \%$, respectively). Figure 5 has summarized the responses of patients.

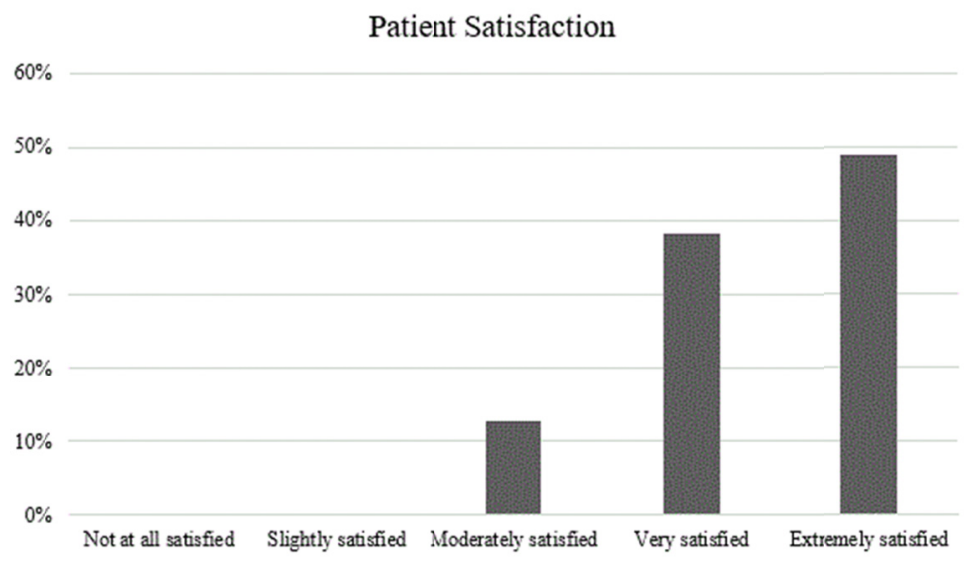

Figure 5. Patient satisfaction

\section{Discussion}

The study conducted by Asarnow et al. (2015) reported the importance of integrated medical-behavioral primary care. The results of the study showed that the following integration helps in improving the youth behavioral health outcomes. Moreover, the results suggested that such integration can also be helpful in improving their confidence. Hence, the following study provided significant outcomes for the patients suffering from any mental disorder, also, it was highlighted that children and adolescents health can be improved significantly by such integration with the primary care. On the other hand, the study conducted by Cummings (2016) also described the effectiveness of behavioral health care integration with primary care. The results of the study were found to be consistent with the findings of the current study showing that following integration is useful for reducing the surgical and medical costs associated with the treatment. However, the results also showed that the suggestions of the researchers were contradicting, i.e. few reported positive relationship between medical cost and treatment of patients; whereas, other reported no relationship between these factors.

Another study conducted by Muskett (2014) reported the importance of using Trauma-informed care to support 
mental treatment of patients. The following treatment procedure was found to be effective for patients who have encountered severe trauma in their life. Therefore, this technique was suggested to be an effective treatment plan to help such survivors overcome the trauma without concurring any severe practices. Moreover, Kolko and Perrin (2014) also reported the importance of the integration of behavioral health in the primary care. Thus, the integration of behavioral health into pediatric healthcare can prove to be significant in improving the overall outcomes associated with the health of children. A significant support, clinical utility, acceptance, and feasibility was found among the patients who were undergoing behavioral problems.

To this end, it can be suggested that the integration of behavioral health care in the primary setting helps in improving the overall mental health of the patients. Furthermore, the medical cost of the treatment can also be reduced due to the implication of this system. Moreover, a large acceptance and patient satisfaction also shows the importance of the system. Thus, the following research holds significance since the results obtained from the study can be utilized by the practitioners to implement such integration in the primary care to help the patients in overcoming the mental health problems.

\section{Conclusion}

The present study had explored the process, outcomes of primary care, and barriers that make the primary care access difficult for the patients. The results have concluded that high rates of physical health conditions cause susceptical gaps within the fragmented care. There are significant gaps within the healthcare setting for the patients with serious mental illness and substance use disorder due to fragmentation of the physical and mental care delivery systems. This has resulted in increase of health care utilization and cost. Increased rates of physical health condition have been proportionalized, making them vulnerable to the gaps in fragmented care. Moreover, care among these patients is a major driver for health care costs. The results have shown that there is positive impact of co-locating primary care in behavioral health settings on outcomes for individuals with serious mental illness. The results concluded that the most common reason preventing the patients from accessing the primary care services was the transportation barrier. The integration has resulted in improving the access and reduced the cost of health care services. The number of ER visits has declined significantly after enrolling in the new clinic with a cost saving of more than $\$ 800,000$ in a six-month period. For adults with diabetes, their blood sugar levels were not well controlled (baseline $\mathrm{HbA} 1 \mathrm{c}>7 \mathrm{mml} / \mathrm{L}$ ) and there was no available data of their follow up HbA1c.

\section{Limitations}

The study was conducted in a short time period after the integration process. The study results showed promising effects; however, the integration process should be assessed at least after one year to ensure all aspects of the integration are fulfilled appropriately. The other limitation of the study is the subjectivity of some of the measures that need further follow with more objective measure. Unavailability of some data such as follow up HbA1c made the assessment of the physical health difficult. In addition, the timeframe for the study was short comparing to the measures that have been used.

\section{Recommendations}

Local health departments and local providers should develop and facilitate health education programs to the susceptible population especially those with severe mental illnesses. The electronic medical records system of the clinic should be integrated with the behavioral clinic to reach a full integration (level 5 or 6 ). The sharing of mental health information should depend on the legal advice obtained regarding the sharing of mental health information obtained regarding the sharing of mental health information. Policy makers and community leaders should advocate to promote the social well-being of the community and ensure that their basic needs are met. Health education is an important strategy to promote the physical well-being of the individuals. Behaviorists in this setting should provide the patient with pertinent information to address the need of having a primary care physician to prevent and monitor some of the risk factors that might exacerbate the mental illness. The clinic needs to ensure full documentation of all of the laboratory needs, adopt clinical guidelines, and assess the patient compliance to their appointments.

\section{Acknowledgements}

I wish to express my sincere thanks to Dr. Daniel J. West, Jr., PhD., FACHE, FACMPE (Professor and Chairman-Department of Health Administration and Human Resources) at the University of Scranton and Mrs. Teresa Lacey, Sr. Vice President Quality and Safety at The Wright Center, for providing me with all the necessary facilities and directed supervision for the project. 


\section{Funding}

The research is not funded through any source.

\section{Competing Interests Statement}

The authors declare no competing interest.

\section{References}

Asarnow, J. R., Rozenman, M., Wiblin, J., \& Zeltzer, L. (2015). Integrated medical-behavioral care compared with usual primary care for child and adolescent behavioral health: a meta-analysis. JAMA pediatrics, 169(10), 929-937. https://doi.org/10.1001/jamapediatrics.2015.1141

Bakitas, M. A., Tosteson, T. D., Li, Z., Lyons, K. D., Hull, J. G., Li, Z., \& Azuero, A. (2015). Early versus delayed initiation of concurrent palliative oncology care: patient outcomes in the ENABLE III randomized controlled trial. Journal of Clinical Oncology, 33(13), 1438. https://doi.org/10.1200/jco.2014.58.6362

Callahan, C. M., Kroenke, K., Counsell, S. R., Hendrie, H. C., Perkins, A. J., Katon, W., ... \& IMPACT investigators. (2005). Treatment of depression improves physical functioning in older adults. Journal of the American Geriatrics Society, 53(3), 367-373. https://doi.org/10.1111/j.1532-5415.2005.53151.x

Corrigan, P. W., Druss, B. G., \& Perlick, D. A. (2014). The impact of mental illness stigma on seeking and participating in mental health care. Psychological Science in the Public Interest, 15(2), 37-70. https://doi.org/10.1177/1529100614531398

Cummings, N. A. (2016). Behavioral health in primary care: Dollars and sense. In Psyche's Prophet (pp. 141-155). Routledge.

Cummings, N. A., \& Cummings, J. L. (1997). The behavioral health practitioner of the future: The efficacy of psychoeducational programs. Behavioral health in primary care: A guide for clinical integration, 325-346.

Gilbody, S., Bower, P., Fletcher, J., Richards, D., \& Sutton, A. J. (2006). Collaborative care for depression: a cumulative meta-analysis and review of longer-term outcomes. Archives of internal medicine, 166(21), 2314-2321. https://doi.org/10.1001/archinte.166.21.2314

Katon, W., Von Korff, M., Lin, E., Walker, E., Simon, G. E., Bush, T., \& Russo, J. (1995). Collaborative management to achieve treatment guidelines: impact on depression in primary care. Jama, 273(13), 1026-1031. https://doi.org/10.1001/jama.1995.03520370068039

Kolko, D. J., \& Perrin, E. (2014). The integration of behavioral health interventions in children's health care: Services, science, and suggestions. Journal of Clinical Child \& Adolescent Psychology, 43(2), 216-228. https://doi.org/10.1080/15374416.2013.862804

Muskett, C. (2014). Trauma-informed care in inpatient mental health settings: A review of the literature. International journal of mental health nursing, 23(1), 51-59. https://doi.org/10.1111/inm.12012

Pallak, M. S., Cummings, N. A., Dörken, H., \& Henke, C. J. (1994). Medical costs, Medicaid, and managed mental health treatment: the Hawaii study. Managed Care Quarterly, 2(2), 64-70. https://doi.org/10.1002/yd.23319935905

Simon, G. E., \& VonKorff, M. (1997). Is the integration of behavioral health into primary care worth the effort? A review of the evidence.

Stuart, G. W. (2014). Principles and Practice of Psychiatric Nursing-E-Book. Elsevier Health Sciences.

Van Mierlo, L. D., Meiland, F. J., Van Hout, H. P., \& Dröes, R. M. (2014). Towards personalized integrated dementia care: a qualitative study into the implementation of different models of case management. $B M C$ geriatrics, 14(1), 84. https://doi.org/10.1186/1471-2318-14-84

Varcarolis, E. M. (2016). Essentials of Psychiatric Mental Health Nursing-E-Book: A Communication Approach to Evidence-Based Care. Elsevier Health Sciences.

Ward, M. C., Miller, B. F., Marconi, V. C., Kaslow, N. J., \& Farber, E. W. (2016). The role of behavioral health in optimizing care for complex patients in the primary care setting. https://doi.org/10.1007/s11606-015-3499-8 


\section{Appendix A: Data Collection Tool-Patient Survey}

1. Age:

2. Sex:
- Male
- Female

3. Race:
- American Indian or Alaska Native
- Asian
- Black or African American
- Native Hawaiian or Other Pacific Islander
○ White
O Other
- I prefer not to answer

4. Ethnicity:

- Hispanic or Latino

Not Hispanic or Latino

\section{Education:}

- Did not complete high school

- High school/GED

- Some college

- Bachelor's degree

- Master's degree

- Advanced graduate work

- Not sure

6. How many times did seek health care services through ED (Emergency Department) in the last 6 months $\underline{B E F O R E}$ enrolling in the new primary care clinic?
○ 0 times
- 1 time
- 2 times
○ 3 times
- 4 times
- 5 times
- 6 times
- 7 times
- 8 times

7. How many times did seek health care services through ED (Emergency Department) $\underline{\text { AFTER }}$ enrolling in the new primary care clinic?
- 0 times
- 1 time
- 2 times
- 3 times
- 4 times
- 5 times 

- 6 times
- 7 times
- 8 times

8. What are some of the possible reasons that prevented you from accessing primary care services in the past? (Choose all that apply)
- Transportation issues
- Being uncomfortable to be seen by primary care physicians
- Did not realize the importance of primary care clinics
○ I thought my behaviorist will take care of everything
○ Lack of family support
O Other, please specify

9. Are you satisfied with the care being provided to you in the primary care clinic?
- Not at all satisfied
- Slightly satisfied
- Moderately satisfied
- Very satisfied
- Extremely satisfied

\section{Copyrights}

Copyright for this article is retained by the author(s), with first publication rights granted to the journal.

This is an open-access article distributed under the terms and conditions of the Creative Commons Attribution license (http://creativecommons.org/licenses/by/4.0/). 